\title{
Increasing emotional intelligence: (How) is it possible?
}

\author{
Delphine Nelis ${ }^{\mathrm{a}, *}$, Jordi Quoidbach ${ }^{\mathrm{a}}$, Moïra Mikolajczak ${ }^{\mathrm{b}, \mathrm{c}}$, Michel Hansenne ${ }^{\mathrm{a}}$ \\ ${ }^{a}$ Personality and Individual Differences Unit, Department of Cognitive Science, University of Liège, 5 Bd. du Rectorat, 4000 Liège, Belgium \\ ${ }^{\mathrm{b}}$ Research Unit for Emotion, Cognition and Health, Department of Psychology, Université catholique de Louvain, 10 Place Cardinal Mercier, 1348 Louvain-la-Neuve, Belgium \\ ${ }^{\mathrm{c}}$ Belgian National Fund for Scientific Research (FNRS), Belgium
}

\section{A R T I C L E I N F O}

\section{Article history:}

Received 29 October 2008

Received in revised form 23 January 2009

Accepted 28 January 2009

Available online 6 March 2009

\section{Keywords:}

Emotional intelligence

Emotional skills

Intervention

Training

\begin{abstract}
A B S T R A C T
The construct of emotional intelligence (EI) refers to the individual differences in the perception, processing, regulation, and utilization of emotional information. As these differences have been shown to have a significant impact on important life outcomes (e.g., mental and physical health, work performance and social relationships), this study investigated, using a controlled experimental design, whether it is possible to increase EI. Participants of the experimental group received a brief empirically-derived EI training (four group training sessions of two hours and a half) while control participants continued to live normally. Results showed a significant increase in emotion identification and emotion management abilities in the training group. Follow-up measures after 6 months revealed that these changes were persistent. No significant change was observed in the control group. These findings suggest that EI can be improved and open new treatment avenues.
\end{abstract}

(c) 2009 Elsevier Ltd. All rights reserved.

\section{Introduction}

Research devoted to emotional intelligence has now split off into two distinct perspectives. Both perspectives share the idea that cognitive abilities are not the unique predictor of successful adaptation but that emotional competencies have to be taken into consideration. However, these perspectives markedly differ regarding their conceptualisation of such emotional competencies and their measurement (Mikolajczak, Luminet, \& Menil, 2006). On the one hand, ability models (Mayer \& Salovey, 1997) conceive EI as an ability encompassing four dimensions: (a) emotions identification; (b) emotions utilization; (c) emotions understanding and (d) emotions regulation. In this ability perspective, EI is assessed via intelligence-like tests. On the other hand, trait models (Petrides \& Furnham, 2001) consider EI as a multifaceted construct encompassing 13-15 (depending on the model) emotion-related behavioural dispositions thought to affect the ways an individual would cope with demands and pressures. In this trait perspective, EI is evaluated via personality-like questionnaires. While ability tests capture maximal performance, trait tests aim to capture typical performance (see Petrides \& Furnham, 2003).

Past debates on the status of EI as intelligence (ability) or trait (disposition) has given birth to a tripartite model of EI (see Mikolajczak, Petrides, Coumans, \& Luminet, in press). Briefly, this model posits three levels of EI: knowledge, abilities and traits. The knowledge level refers to the complexity and width of emotion

\footnotetext{
* Corresponding author. Tel.: +32 (0)4 366 3456; fax: +32 (0)4 3662859

E-mail address: delphine.nelis@ulg.ac.be (D. Nelis).
}

knowledge. The focus is on what people know about emotions and how to deal with emotion-laden situations. The ability level refers to the ability to apply emotion knowledge in an emotional situation and to implement a given strategy. The focus here is not on what people know but on what they can do. For instance, even though many people know that distraction is an efficient strategy to reduce anger, lots of them are simply not able to distract themselves when angry. The trait level refers to emotion-related dispositions, namely, the propensity to behave in a certain way in emotional situations. The focus here is not on what people know or can do, but on what they do. For instance, some individuals may be able to distract themselves from a situation that makes them angry if explicitly asked to do so, while not managing to distract themselves of their own volition. These three levels of EI are loosely connected: knowledge does not always translate into abilities, which, in turn, do not always translate into practice. In view of this, the training was aimed to modify people's dispositions.

A growing number of scientific investigations started to empirically measure the effects of EI on life quality, academic/occupational success, resistance to stress, health and the quality of social/marital relationships, to name but the few most significant outcomes. Taken together, these studies indicate that EI is an active and essential ingredient of life success and happiness.

A vast amount of research has documented a positive association between trait EI and well-being related variables (e.g., Petrides, Pita, \& Kokkinaki, 2007; Schutte, Malouff, Simunek, McKenley, \& Hollander, 2002). Trait EI is negatively related to psychopathology (e.g., Malterer, Glass, \& Newman, 2008). Trait EI was also a significant moderator of responses to stress (e.g., 
Mikolajczak \& Luminet, 2008; Mikolajczak, Roy, Luminet, Fillée, \& de Timary, 2007).

Student academic commitment and success have also been related to EI in a variety of studies. Individuals with higher levels of trait EI get higher test scores and grades (Jaeger, 2003) and were less likely to have been excluded from school (Petrides, Frederickson, \& Furnham, 2004). Trait EI is implicated in academic performance and deviant behaviour, with effects that are particularly relevant to vulnerable students. Finally, ability and trait EI has been found to be associated with job performance and occupational success, especially for jobs involving high levels of interpersonal contacts, such as service workers (sales persons, nurses, call operators, ...) (see for a review Daus \& Ashkanasy, 2005; Van Rooy \& Viswesvaran, 2004). At group level, trait EI has been found to be related to team performance and group cohesiveness (see Quoidbach \& Hansenne, 2009).

In view of this, interventions designed to improve EI have recently bloomed particularly among children's, managers and subjects with affective difficulties (Matthews, Zeidner, \& Roberts, 2002). Despite the huge expansion of EI development methods and the preliminary evidence for their effectiveness - especially with children (Zins, Weissberg, Wang, \& Walberg, 2004) - ,very few EI programs are based on a solid theoretical model and even fewer have been rigorously tested (Matthews et al., 2002). First, these trainings lack a clear theoretical and methodological rationale and employ a miscellany of techniques whose psychological bases are sometimes dubious (Matthews et al., 2002; Matthews, Zeidner, \& Roberts, 2007). Second, they usually target only some EI dimensions (e.g., target emotion identification but not emotion management) and add a number of skills which are not considered as parts of EI, such as problem resolution, alcohol or drugs prevention, and reduction of violence (e.g., Topping, Holmes, \& Bremmer, 2000). Third, when evaluations of these programs exist, they are often limited to subjective impression right after the training given by teachers for EI training at school or by the director for EI training at work, without considering the long-term effects (Aber, Brown, \& Henrich, 1999; Goleman, 1995; Matthews et al., 2002). Finally, none of the EI trainings' evaluations to date included a control group.

The main goal of our study is to investigate whether EI can be improved among young adults. More specifically, we tested, using a controlled design, the impact of a theoretically based training on the different components of EI. A second goal of the study is to determine whether the benefits of the training depend or not on the initial level of EI.

The intervention developed for this study focused on teaching theoretical knowledge about emotions and on training participants to apply specific emotional skills in their everyday life. Sessions were articulated according to Mayer and Salovey's (1997) fourbranches model, and empirical findings were systematically used to inform each teaching module. For example, Scherer's (2001) model on the multiple components of emotion and Ekman and Friesen (1971) work on facial expressions informed a large part of the perception of emotion in oneself and in others' sequences respectively, and findings on effective emotion regulation strategies (Gross, 1998) were used to develop a large part of the emotional regulation training.

\section{Method}

\subsection{Participants}

The sample consisted of 37 participants, 19 in the training group and 18 in the control group. There were 15 women and four men in the training group with a mean age of 21 years $(S D=3.42)$.
The control group consisted of 15 women and three men with a mean age of 20.5 years $(S D=1.46)$. All participants were psychology students, who gave written informed consent to participate in the study.

\subsection{Measures}

The effectiveness of the intervention was assessed through a global measure of trait EI as well as various measures aiming to assess independently the different branches of EI.

Global Trait Emotional Intelligence was assessed using the French version of the Trait Emotional Intelligence Questionnaire (TEIQue; Petrides, 2009). The TEIQue consisted of 153 items arranged on a 7point response scale (from strongly agree to strongly disagree). It provides scores for 15 subscales, four factors (well-being, self-control, emotionality, and sociability) and global trait EI. The TEIQue shows excellent psychometric properties (see Mikolajczak, Luminet, Leroy, \& Roy, 2007, for the psychometric properties of the French adaptation used in this study). In this study, the internal consistency of the global score was 0.82 .

Emotion Regulation (own emotions) was assessed through the Emotion Regulation Profile Questionnaire (ERP-Q; Mikolajczak, Nélis, Hansenne, \& Quoidbach, 2008; Nélis, Quoidbach, Hansenne, \& Mikolajczak, in preparation). The ERP-Q is a vignette-based measure comprising 12 scenarios targeting 6 emotion categories: anger/irritation, sadness/nostalgia, fear/anxiety, jealousy/envy, shame/guilt and joy/plenitude. Each scenario is associated with 6 possible reactions: three considered as adaptive in the literature (e.g., positive reappraisal, social support seeking, and acceptance) and three viewed as maladaptive (avoidance, substance abuse, rumination). Respondents were required to circle, for each scenario, the two strategies they would most likely use and the two strategies they would most likely not use. Respondents were credited 1 point when selecting a functional strategy or rejecting a dysfunctional strategy, and -1 point when selecting a dysfunctional strategy or rejecting a functional strategy. The $\alpha$ was 0.72 in the current sample.

Regulation of others' emotions was assessed with the Emotional Management Abilities test (EMA; Freudenthaler \& Neubauer, 2005; French adaptation by Nélis (2007)). The EMA contained 42 items, of which 18 assess the ability to manage one's own emotions (intrapersonal) and 24 assess the ability to manage others' emotions (interpersonal). Both scales consist of scenarii describing emotional situations. Respondents had to choose among four possible reactions, with different levels of efficiency. The efficiency of each reaction was determined by experts in the field of emotions. In this study, we have only used items which assess the ability to manage others' emotions ( $\alpha=0.48$ for managing others' emotions).

Emotion identification was measured through the Dimensions of Openness to Emotional experiences -trait version (DOE; Reicherts, 1999) and the Toronto Alexithymia Scale (TAS-20; Bagby, Parker, \& Taylor, 1994; French adaptation: Loas, Otmani, Verrier, Fremaux, \& Marchand, 1996).

The DOE measures individual differences in awareness of internal and external indicators of emotion as well as cognitive/conceptual representation of affective states. The measure consisted of a 36-item questionnaire assessing 6 main dimensions of emotion processing (conceptual representation (REPCON), communication and expression of emotions (EMOCOM), perception of bodily indicators (PERINT), perception of external bodily indicators (PEREXT) emotion regulation (REGEMO), normative limitations of emotional openness (RESNOR)). The internal consistency of the global score was 0.66 in the present study.

The TAS-20 consists of 20 items responded to on a 5-point scale ( 1 = strongly agree to $5=$ strongly disagree). It provides a global score as well as scores on three specific dimensions: difficulty in 
identifying feelings, difficulty in describing feelings, and externally-oriented thinking. The internal consistency of the global score was 0.82 in the present study.

Emotional understanding was evaluated by means of the Situational Test of Emotional Understanding (STEU; MacCann \& Roberts, 2008). The STEU is based on the Roseman's model (2001) of the emotions system. According to this model, the 17 most common emotions can be explained by a combination of seven appraisal dimensions. The STEU comprised 42 items with 14 decontextualized items, 14 workplace-related items and 14 private life-related items. Each item presents an emotional situation, and participants had to choose which emotion the situation will most likely elicit. The internal consistency of this French version was low $(\alpha=0.33)$ in the present study.

\subsection{EI intervention}

The EI intervention consisted of four sessions of two and half hours over a 4-week period. There were two training groups; one comprising 10 participants and the other one 9 participants. Each session was at a 1-week interval. This interval allowed participants to apply what was taught during sessions in their daily life. In contrast to other studies that improve EI without theatrical references and limited to one aspect of EI, the design of our training was based on Mayer and Salovey's four-branch model of Elias et al. (1997): (1) perception, appraisal, and expression of emotion; (2) emotional facilitation of thinking; (3) understanding and analysing emotions; (4) reflective regulation of emotion. During the program, techniques to enhance these skills, especially emotional regulation (intrapersonal and interpersonal) and emotional understanding were instructed. The content of each session was based on short lectures, role plays, group discussions, two-person works, and readings. The participants were also provided with a personal diary in which they had to report daily one emotional experience. These emotional experiences had to be analysed in light of the theory explained in class. The outline of the sessions is set out in the Appendix.

\subsection{Procedure}

The participants completed all the measures three times: prior to session 1, at the end of session 4 (i.e., right after the training), and 6 months later to have a long-term post training evaluation. Indeed, research shows that knowledge acquired during group training can take up to 6 months to translate into applied skills. As recommended by authorities (see Kirkpatrick, 1998), investigations of the effectiveness of trainings should therefore also include a long-term assessment of skills transfer. All participants attended all the sessions and all of them were blind to their scores throughout the study. The personal diaries were given to the participants at the end of the first session and had to be completed daily until the end of the training. Reminders and readings were given to the participants after each session. Participants of the control group completed the same measures as the training group, but were not exposed to the training.

\section{Results}

Independent $t$-tests showed that there were no baseline differences between the training and the control group on any of the variables under consideration (see Table 1 ).

Mixed model group (training vs. control) $\times$ time (time 1 , time 2 , time 3 ) repeated measures ANOVAs were performed on each measure, with group as between-subject factor and time as withinsubject factor (cf. Figs. 1-3). In each case, we were looking for a group $\times$ time interaction, which would indicate a differential change for the two groups. Analyses yielded a significant group time interaction for the ERP-Q, EMA, and the TAS-20 scales $[(F(2,70)=5.58, \quad p=.005 ; \quad F(2,70)=3, \quad p=.050 ; \quad F(2,70)=4.19$, $p=.024$, respectively] and a marginally significant effect for the TEIQue $[F(2,70)=2.59, p=0.08]$. No significant group $\times$ time interaction was found for the DOE and the STEU scales $[(F(2,70)=1.40$, $p=0.253 ; F(2,70)=0.04, p=0.961$, respectively].

The means, standard deviations and statistics between time 1 , time 2 and time 3 for each variable and each group are shown in Tables 2-4. The training group showed a significant increase on the TEIQue $(t(18)=-2.29, p=.033)$, ERP-Q $\quad(t(18)=-6.81$, $p<.001)$, EMA $(t(18)=-3.45, p=.003)$, DOE $\quad(t(18)=-2.33$, $p=.031)$, and a significant decrease in TAS-20 scores $(t(18)=2.17, p=.043)$ between time 1 and time 2 . No significant difference was found for the STEU scale $(t(18)=-1.75, p=.097)$ (see Table 2). The difference between time 2 and time 3 was non-significant for all variables, suggesting that the improvement evident in the training group remained stable after 6 months (see Table 3). The difference between time 1 and time 3 was significant for all variables suggesting also a long-term increase in the training group after the training (see Table 4 ). The control group showed no significant difference between time 1 and 2, between time 2 and 3 and between time 1 and 3 .

In order to determine whether the benefits of the training were dependent on the initial level of emotional competence, participants were stratified on initial scores of alexithymia, emotion regulation (self), and emotion regulation (others). A median split for each measure was used to create high and low groups for the three above variables. Split-plot ANOVAs were performed on TAS-20, EMA, and ERP-Q, with level (High vs. Low) as the between-subject factor and time (Time 1, 2, and 3 ) as the within-subject factor. Results showed no significant three-way interactions (TAS-20: $p=.163$; EMA: $p=.494$; ERP-Q: $p=.308$ ) suggesting that the benefits of the training did not depend on the initial level of emotional competence.

\section{Discussion}

The purpose of the present study was to investigate whether EI could be developed among young adults using a proper

Table 1

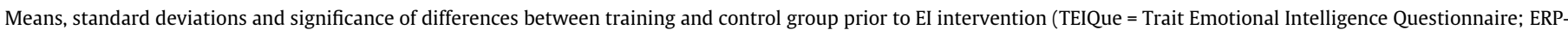

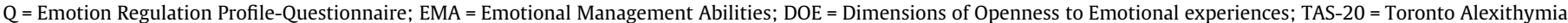
Scale-20; STEU = Situational Test of Emotional Understanding).

\begin{tabular}{|c|c|c|c|}
\hline Variables & Training group $(N=19)$ & Control group $(N=18)$ & \\
\hline TEIQue & $652.47(59.41)$ & $661.11(55.81)$ & $t(35)=-0.48, p=.631$ \\
\hline ERP-Q & $20.31(10.73)$ & $22.11(11.43)$ & $t(35)=-0.49, p=.625$ \\
\hline EMA & $76.11(1.38)$ & $76.83(5.77)$ & $t(35)=-0.18, p=.812$ \\
\hline DOE & $73.68(10.82)$ & $73.72(9.13)$ & $t(35)=-0.01, p=.991$ \\
\hline TAS-20 & $47.53(9.31)$ & 44.88 (10.89) & $t(35)=0.79, p=.432$ \\
\hline STEU & $25.84(2.96)$ & $26.88(2.67)$ & $t(35)=-0.97, p=.338$ \\
\hline
\end{tabular}




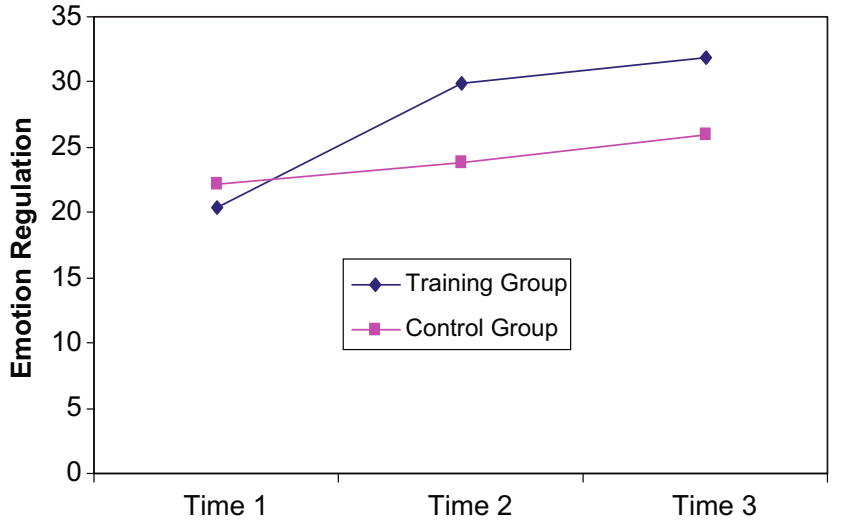

Fig. 1. Effect of EI intervention on emotion regulation across three times (time 1 = before training; time 2 =after training; time 3=6 months after training) of evaluation for the two groups (training and control group).

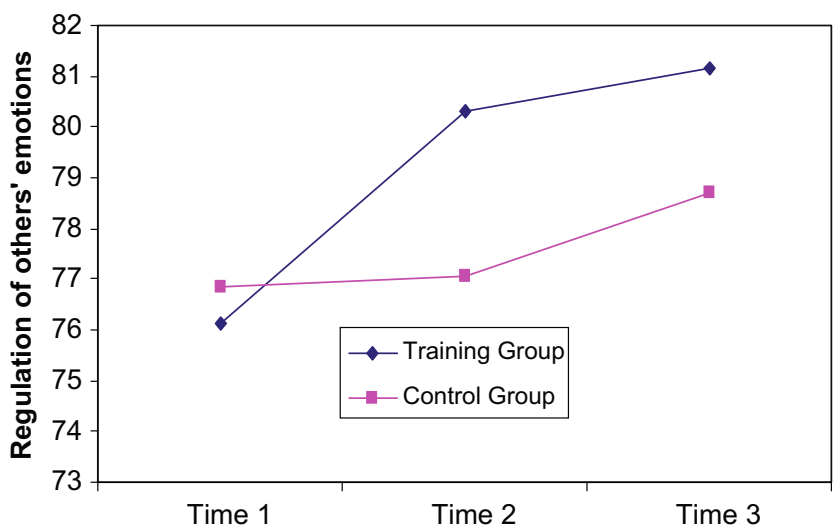

Fig. 2. Effect of EI intervention on regulation of others' emotions across three times (time 1 = before training; time 2 = after training; time $3=6$ months after training) of evaluation for the two groups (training and control group).

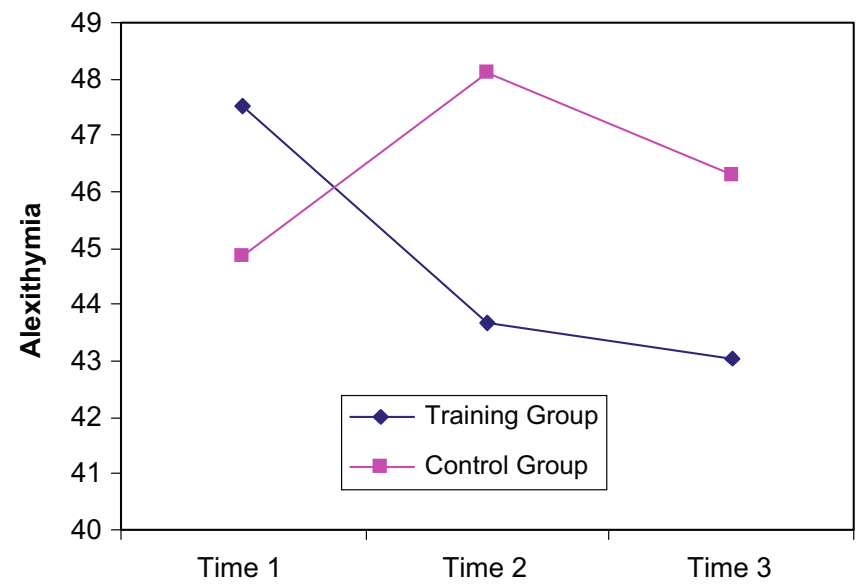

Fig. 3. Effect of EI intervention on alexithymia across three times (time 1 = before training; time 2 = after training; time $3=6$ months after training) of evaluation for the two groups (training and control group).

experimental design and a theoretically grounded training program. To our knowledge, this study is the first attempt to assess whether EI can be trained in a French-speaking sample. The major finding of the study is that the training group (but not the control group) scored significantly higher on trait emotional intelligence (TEIQue) after the training. Compared to the control group, the
Table 2

Means, standard deviations and significance of differences between time 1 and time 2 for each variable and each group (TEIQue = Trait Emotional Intelligence Questionnaire; ERP-Q = Emotion Regulation Profile-Questionnaire; EMA = Emotional Management Abilities; $\mathrm{DOE}=$ Dimensions of Openness to Emotional experiences; TAS$20=$ Toronto Alexithymia Scale-20; STEU $=$ Situational Test of Emotional Understanding).

\begin{tabular}{|c|c|c|c|}
\hline Variables & Time 1 & Time 2 & \\
\hline \multicolumn{4}{|c|}{ Training group $(N=19)$} \\
\hline TEIQue & $652.47(59.41)$ & $673.78(59.81)$ & $t(18)=-2.29, p=.033$ \\
\hline ERP-Q & $20.31(10.73)$ & $29.89(9.76)$ & $t(18)=-6.81, p<.001$ \\
\hline EMA & $76.11(6.13)$ & $80.31(5.56)$ & $t(18)=-3.45, p=.003$ \\
\hline DOE & $73.68(10.82)$ & 77.05 (10.29) & $t(18)=-2.33, p=.031$ \\
\hline TAS-20 & $47.53(9.31)$ & $43.68(9.25)$ & $t(18)=2.17, p=.043$ \\
\hline STEU & $25.84(2.96)$ & $27.05(3.01)$ & $t(18)=-1.75, p=.097$ \\
\hline \multicolumn{4}{|c|}{ Control group $(N=18)$} \\
\hline TEIQue & $661.11(55.81)$ & $661.78(50.11)$ & $t(17)=-0.13, p=.898$ \\
\hline ERP-Q & $22.11(11.43)$ & $23.77(12.59)$ & $t(17)=-0.72, p=.477$ \\
\hline EMA & $76.83(5.77)$ & $77.05(5.17)$ & $t(17)=-0.24, p=.814$ \\
\hline DOE & $73.72(9.13)$ & $73.94(9.66)$ & $t(17)=-0.16, p=.871$ \\
\hline TAS-20 & $44.88(10.89)$ & $48.11(12.36)$ & $t(17)=-1.77, p=.097$ \\
\hline STEU & $26.88(3.57)$ & $28(2.67)$ & $t(17)=-1.22, p=.235$ \\
\hline
\end{tabular}

Table 3

Means, standard deviations and significance of differences between time 2 and time 3 for each variable and each group (TEIQue = Trait Emotional Intelligence Questionnaire; ERP-Q = Emotion Regulation Profile-Questionnaire; EMA = Emotional Management Abilities; $\mathrm{DOE}=$ Dimensions of Openness to Emotional experiences; TAS$20=$ Toronto Alexithymia Scale-20; STEU $=$ Situational Test of Emotional Understanding)

\begin{tabular}{llll}
\hline Variables & Time 2 & Time 3 & \\
\hline Training group & $(N=19)$ & & \\
TEIQue & $673.78(59.81)$ & $685.36(56.03)$ & $t(18)=-1.05, p=.308$ \\
ERP-Q & $29.89(9.76)$ & $31.87(11.70)$ & $t(18)=-1.31, p=.205$ \\
EMA & $80.31(5.56)$ & $81.16(5.30)$ & $t(18)=-0.61, p=.551$ \\
DOE & $77.05(10.29)$ & $78.78(8.86)$ & $t(18)=-0.76, p=.453$ \\
TAS-20 & $43.68(9.25)$ & $43.05(6.53)$ & $t(18)=0.41, p=.688$ \\
STEU & $27.05(3.01)$ & $27.57(3.25)$ & $t(18)=-0.83, p=.416$ \\
Control group $(N=18)$ & & \\
TEIQue & $661.78(50.11)$ & $661.59(46.09)$ & $t(17)=0.01, p=.998$ \\
ERP-Q & $23.77(12.59)$ & $26.00(11.64)$ & $t(17)=-0.02, p=.979$ \\
EMA & $77.05(5.17)$ & $78.70(3.51)$ & $t(17)=-1.54, p=.143$ \\
DOE & $73.94(9.66)$ & $74.52(9.79)$ & $t(17)=0.17, p=.859$ \\
TAS-20 & $48.11(12.36)$ & $46.29(12.36)$ & $t(17)=-0.43, p=.666$ \\
STEU & $28(2.67)$ & $28.35(4.19)$ & $t(17)=0.29, p=.767$ \\
\hline
\end{tabular}

Table 4

Means, standard deviations and significance of differences between time 1 and time 3 for each variable and each group (TEIQue = Trait Emotional Intelligence Questionnaire; ERP-Q = Emotion Regulation Profile-Questionnaire; EMA = Emotional Management Abilities; $\mathrm{DOE}=$ Dimensions of Openness to Emotional experiences; TAS$20=$ Toronto Alexithymia Scale-20; STEU $=$ Situational Test of Emotional Understanding)

\begin{tabular}{llll}
\hline Variables & Time 1 & Time 3 & \\
\hline Training group & $(N=19)$ & & \\
TEIQue & $652.47(59.41)$ & $685.36(56.03)$ & $t(18)=-2.25, p=.036$ \\
ERP-Q & $20.31(10.73)$ & $31.87(11.70)$ & $t(18)=-4.88, p<.001$ \\
EMA & $76.11(6.13)$ & $81.16(5.30)$ & $t(18)=-3.67, p=.002$ \\
DOE & $73.68(10.82)$ & $78.78(8.86)$ & $t(18)=-2.60, p=.017$ \\
TAS-20 & $47.52(9.31)$ & $43.05(6.53)$ & $t(18)=2.64, p=.016$ \\
STEU & $25.84(2.96)$ & $27.57(3.25)$ & $t(18)=-2.45, p=.024$ \\
Control group $(N=18)$ & & \\
TEIQue & $661.11(55.81)$ & $661.59(46.09)$ & $t(17)=-0.02, p=.981$ \\
ERP-Q & $22.11(11.43)$ & $26.00(11.64)$ & $t(17)=0.99, p=.325$ \\
EMA & $76.83(5.77)$ & $78.70(3.51)$ & $t(17)=-2.02, p=.065$ \\
DOE & $73.72(9.13)$ & $74.52(9.79)$ & $t(17)=0.25, p=.802$ \\
TAS-20 & $44.88(10.89)$ & $46.29(12.36)$ & $t(17)=0.35, p=.723$ \\
STEU & $26.88(3.57)$ & $28.35(4.19)$ & $t(17)=1.11, \mathrm{p}=.727$
\end{tabular}


training group showed a significant change in several competences (emotion identification, emotion management) targeted by our program. Understanding emotions was not improved and expressing and using emotions were not assessed. Apart from emotion understanding which remained unchanged, the training led to a significant improvement in emotion identification and emotion management (self and others' emotions). The lack of change in emotional understanding is amazing. One possible explanation is that our understanding emotion session was not based on Roseman's framework on which STEU was developed. It is noteworthy that the magnitude of the changes was unrelated to the level of emotional intelligence prior to the training.

A major finding of this study is that all positive changes remain significant 6 months after the intervention (while the control group did not improve over time). That is, the changes were not only evident on the short-term but persistent on the long-term. In addition, it is interesting to notice that all the EI variables in this study slightly improved between time 2 and time 3 (although this effect is not significant). Thus, future EI training programs might fruitfully include follow-up coaching sessions to maximize this effect.

Taken together, our results suggest that some emotional abilities and habits may be effectively improved, even using a relatively short training. However, some aspects of EI like emotional understanding was not improved. This finding has important theoretical and practical implications. At the theoretical level, our results suggest that traits that have shown to be relatively stable over time can be modified through intensive training. However, as these traits are precisely relatively stable, it is possible that people would come back to their "baseline" after a while if the competences are not practiced. This should still be investigated and the necessary steps must be taken if need be (e.g., follow-up sessions every now and then to maintain the newly-developed skills). At the practical level, our findings are noteworthy because one's level of emotional competence (or "emotional intelligence") predicts numerous positive outcomes in the realm of health, social relationships, performance, and psychological well-being (Greven, Chamorro-Premuzic, Arteche, \& Furnham, 2008; Schutte, Malouff, Thorsteinsson, Bhullar, \& Rooke, 2007; Smith, Heaven, \& Ciarrochi, 2008).

Trait EI theory considers EI as a constellation of emotion-related self-perceptions and dispositions located at the lower levels of personality hierarchies (Petrides \& Furnham, 2001). One tenet of this conceptualisation is that there are situations in which high trait EI scores will be linked with maladaptive outcomes (Petrides \& Furnham, 2003; Sevdalis, Petrides, \& Harvey, 2007). For example, Petrides and Furnham (2003) found that high trait EI participants exhibited greater sensitivity to the mood induction procedure. Indeed, high trait EI participants have greater mood deterioration than low trait EI participants following the presentation of a short disturbing clip. High trait EI individuals may have an increased sensitivity to affect-laden stimuli over their low trait EI peers. High trait EI individuals also showed a reduction of positive affect and an increase of negative affect over low trait EI individuals after recalling a past decision that led to intense negative affect. In consequence, this increased sensitivity may not be beneficial in all contexts and can lead to an increased susceptibility to interference from emotion evoking stimuli in learning or memory tasks (Petrides \& Furnham, 2003).

This study breaks new ground in several ways, which leaves ample room for future research to probe or refine its findings. First, the sample was small and predominantly composed of females and included students from the same faculty (i.e., psychology), which limits the generalizability of the results. Second, our control group was composed of matched participants who did not take part in any group activity. This experimental design can inadvertently have created experimenter demand, expectation of improvement, or nonspecific effects related to processes such as contact with a caring instructor or social support and friendship provided by the group. Third, no instrument has been included to assess the improvement in the Emotional Facilitation branch of the EI model because such instruments are not available except MSCEIT but with poor psychometric properties (Rossen, Kranzler, \& Algina, 2008). Fourth, the low internal consistency showed by some of the instruments (i.e., EMA, STEU) limits the reliability of the results. However, results showing an improvement on almost all the dimensions of EI lasting over 6 months advocate for a real effect of the training beside these potential biases.

Future work would benefit from replicating these results with a larger and more heterogeneous sample as well as from directly controlling nonspecific effects and expectancies by comparing the present training to other group or self-change activities. Additionally, future research projects on EI development might interestingly include some objective measures of individual differences in emotional processing (e.g., cortisol, frontal asymmetry, fMRI changes) and some measures of EI correlates (e.g., health, social or performance-related outcomes).

Overall, the results are promising as they suggest that, with a proper methodology relying on the latest scientific knowledge about emotion and emotional processing, some facets of EI can be enhanced but not all. Potential application of this intervention in health, educational, and organisational settings offers a new approach in developing and promoting human fulfilment.

\section{Appendix. Outline of EI training sessions}

\section{Session 1: Understanding emotions}

- Role play illustrating the importance of emotions and EI.

- Introductions/Welcome/Explanation of the sessions and the use of the personal diary.

- Explanation of key concepts (emotions, emotional intelligence).

- Summary and homework.

\section{Session 2: Identifying emotions}

- Review of previous session and homework.

- Identifying one's emotions using three doors (i.e., physiological activation, cognitions and action tendencies in Scherer's five components of emotion): theory and practice.

- Identifying others' emotions through facial expression decoding: drill with the METT program.

- Identifying others' emotions (continue): asking the right question and empathic.

- Communication.

- Summary and homework.

Session 3: Expressing and using emotions

- Review of previous session and homework.

- How to express emotions: facts - emotions - need - positive solutions.

- Role play.

- Using the power of positive emotions: how to improve one's positive feelings (e.g., gratefulness).

- Using emotions to solve problems: the emotional roadmap.

- Summary and homework.

Session 4: Managing emotions

- Review of previous session and homework.

- Coping strategies and their effectiveness: theory and group discussion. 
- Positive reappraisal: role play and drill.

- Mind-body connections and relaxation exercises.

- Summary/Questions/Evaluation.

\section{References}

Aber, J. L., Brown, J. L., \& Henrich, C. C. (1999). Teaching conflict resolution: An effective school-based approach to violence prevention. New York: National Center for Children in Poverty, Colombia University.

Bagby, R. M., Parker, J. D., \& Taylor, G. J. (1994). The twenty item Toronto Alexithymia Scale-2: Convergent, discriminant and concurrent validity. Journal of Psychosomatic Research, 38, 33-40.

Daus, C. S., \& Ashkanasy, N. M. (2005). The case for an ability-based model of emotional intelligence in organizational behavior. Journal of Organizational Behavior, 26, 453-466.

Ekman, P., \& Friesen, W. V. (1971). Constants across cultures in the face and emotion. Journal of Personality and Social Psychology, 17, 124-129.

Elias, M. J., Zins, J. E., Weissberg, R. P., Frey, K. S., Greenberg, M. T., Haynes, N. M. et al. (1997). Promoting social and emotional learning: Guidelines for educators. Alexandria, VA: Association for Supervision and Curriculum Development.

Freudenthaler, H. H., \& Neubauer, A. C. (2005). Emotional intelligence. The convergent and discriminant validities of intra and interpersonal emotional abilities. Personality and Individual Differences, 39, 569-579.

Goleman, D. (1995). Emotional intelligence. New York: Bantam Books.

Greven, C., Chamorro-Premuzic, T., Arteche, A., \& Furnham, A. (2008). A hierarchical integration of dispositional determinants of general health in students: The big five, trait emotional intelligence and humour styles. Personality and Individual Differences, 44(7), 1562-1573.

Gross, J. J. (1998). The emerging field of emotion regulation: An integrative review Review of General Psychology, 2(3), 271-299.

Jaeger, A. J. (2003). Job competencies and the curriculum: An inquiry into emotional intelligence in graduate professional education. Research in Higher Education, 44(6), 615-639.

Kirkpatrick, D. (1998). Evaluating training programs: The four levels (2nd ed.). San Francisco, CA: Berrett-Koehler Publishers.

Loas, G., Otmani, O., Verrier, A., Fremaux, D., \& Marchand, M. P. (1996). Factor analysis of the French version of the 20-Item Alexithymia scale (TAS-20) Psychopathology, 29, 139-144.

MacCann, C., \& Roberts, R. D. (2008). New paradigms for assessing emotional intelligence: Theory and data. Emotion, 8(4), 540-551.

Malterer, M. B., Glass, S. J., \& Newman, J. P. (2008). Psychopathy and trait emotional intelligence. Personality and Individual Differences, 44(3), 735-745.

Matthews, G., Zeidner, M., \& Roberts, R. D. (2002). Emotional intelligence: Science and myth. Cambridge, MA: MIT Press.

Matthews, G., Zeidner, M., \& Roberts, R. D. (2007). The science of emotional intelligence: Knowns and unknowns. USA: Oxford University Press.

Mayer, J. D., \& Salovey, P. (1997). What is emotional intelligence? In P. Salovey \& D. J. Sluyter (Eds.), Emotional development and emotional intelligence: Educational implications (pp. 3-31). New York: Basic Books.

Mikolajczak, M., Petrides, K. V., Coumans, N., \& Luminet, O. (in press). An experimental investigation of the moderating effect of trait emotional intelligence on laboratory-induced stress. Journal of Research in Personality.

Mikolajczak, M., \& Luminet, O. (2008). Trait emotional intelligence and the cognitive appraisal of stressful events: An exploratory study. Personality and Individual Differences, 44(7), 1445-1453.

Mikolajczak, M., Luminet, O., Leroy, C., \& Roy, E. (2007). Psychometric properties of the trait emotional intelligence questionnaire: Factor structure, reliability construct, and incremental validity in a French-speaking population. Journal of Personality Assessment, 88, 338-353.

Mikolajczak, M., Luminet, O., \& Menil, C. (2006). Predicting resistance to stress: Incremental validity of emotional intelligence over and above alexithymia and optimism. Psicothema, 18, 79-88.
Mikolajczak, M., Nélis, D., Hansenne, M., \& Quoidbach, J. (2008). If you can regulate sadness, you can probably regulate shame: associations between trait emotional intelligence, emotion regulation and coping efficiency across discrete emotions. Personality and Individual Differences, 44, 1356-1368.

Mikolajczak, M., Roy, E., Luminet, O., Filleee, C., \& de Timary, P. (2007). The moderating impact of emotional intelligence on the free cortisol responses to stress. Psychoneuroendocrinology, 32, 1000-1012.

Nélis, D. (2007). French translation of the Emotional Management Abilities (EMA) test. Unpublished work.

Nélis, D., Quoidbach, J., Hansenne, M., \& Mikolajczak, M. (in preparation). Emotion Regulation Profile-Questionnaire.

Petrides, K. V. (2009). Technical manual for the Trait Emotional Intelligence Questionnaire (TEIQue; 1st ed., 1st printing). London: London Psychometric Laboratory.

Petrides, K. V., Frederickson, N., \& Furnham, A. (2004). The role of trait emotional intelligence in academic performance and deviant behaviour at school. Personality and Individual Differences, 36, 277-293.

Petrides, K. V., \& Furnham, A. (2001). Trait emotional intelligence: Psychometric investigation with reference to established trait taxonomies. European Journal of Personality, 17, 39-75.

Petrides, K. V., \& Furnham, A. (2003). Trait emotional intelligence: Behavioural validation in two studies of emotion recognition and reactivity to mood induction. European Journal of Personality, 17, 39-57.

Petrides, K. V., Pita, R., \& Kokkinaki, F. (2007). The location of trait emotional intelligence in personality factor space. British Journal of Psychology, 98, 273-289.

Quoidbach, J., \& Hansenne, M. (2009). The impact of trait emotional intelligence on nursing team performance and cohesiveness. Journal of Professional Nursing, 25(1), 23-29.

Reicherts, M. (1999). Dimensions de l'ouverture émotionnelle (DOE). Concept théorique, instrument et validation. In 8th Congress of the Swiss Society of Psychology; Fribourg.

Roseman, I. J. (2001). A model of appraisal in the emotion system. In A. S. Klaus Scherer \& T. Johnstone (Eds.), Appraisal processes in emotion: Theory, methods, research (pp. 68-91). New York: Oxford University Press.

Rossen, E., Kranzler, J. H., \& Algina, J. (2008). Confirmatory factor analysis of the Mayer-Salovey-Caruso Emotional Intelligence Test V 2.0 (MSCEIT). Personality and Individual Differences, 44(5), 1258-1269.

Scherer, K. R. (2001). Appraisal considered as a process of multilevel sequential checking. In K. R. Scherer, A. Schorr, \& T. Johnstone (Eds.), Appraisal processes in emotion: Theory, methods, research (pp. 92-120). New York: Oxford University Press.

Schutte, N. S., Malouff, J. M., Simunek, M., McKenley, J., \& Hollander, S. (2002). Characteristic emotional intelligence and emotional well-being. Cognition and Emotion, 16, 769-785.

Schutte, N. S., Malouff, J. M., Thorsteinsson, E. B., Bhullar, N., \& Rooke, S. E. (2007). A meta-analytic investigation of the relationship between emotional intelligence and health. Personality and Individual Differences, 42, 921-933.

Sevdalis, N., Petrides, K. V., \& Harvey, N. (2007). Trait emotional intelligence and decision-related emotions. Personality and Individual Differences, 42, 1347-1358.

Smith, L., Heaven, P., \& Ciarrochi, J. (2008). Trait emotional intelligence, conflict communication patterns and relationship satisfaction. Personality and Individual Differences, 44(6), 1314-1325.

Topping, K., Holmes, E. A., \& Bremmer, W. (2000). The effectiveness of school-based programs for the promotion of social competence. In R. Bar-On \& J. D. Parker (Eds.), The handbook of emotional intelligence: Theory, development, assessment, and application at home, school, and in the workplace (pp. 411-432). San Francisco: Jossey-Bass.

Van Rooy, D. L., \& Viswesvaran, C. (2004). Emotional intelligence: A meta-analytic investigation of predictive validity and nomological net. Journal of Vocational Behavior, 65, 71-95.

Zins, J. E., Weissberg, R. P., Wang, M. C., \& Walberg, H. J. (2004). Building academic success on social and emotional learning: What does the research say? New York: Teachers College Press. 